\title{
Effect of the Addition of Dried Opuntia Cactus Fibers - Setting Times and Mechanical Resistance in Portland Cement Mortar Base
}

\author{
M. Arreola Sanchez ${ }^{1}$, W. Martinez Molina ${ }^{1}$, E. M. Alonso Guzman ${ }^{1}$, H. L. Chavez Garcia ${ }^{1}$, A. A. Torres Acosta ${ }^{2}$, \\ C. Bernabe Reyes ${ }^{1}$, S. C. Arguello Hernandez ${ }^{1}$, C. Lara Gomez ${ }^{1}$, F. M. Gonzalez Valdez ${ }^{1}$, J. A. Velazquez Perez ${ }^{1}$ and \\ R. Ruiz Ruiz ${ }^{1}$ \\ ${ }^{1}$ School of Civil Engineering, Universidad Michoacana de San Nicolás de Hidalgo, Morelia, Michoacan, Mexico, 58040 \\ ${ }^{2}$ Mexican TransportationInstitute, theSecretariat of Communications and Transportation, Sanfandila, Queretaro, Mexico, 76703
}

\begin{abstract}
For this investigation cement-sand mortar and cement-water pastes were made with partial substitutions, relative to the weight of cement, of organic fibres for the purpose of restoring hydraulic concrete structures, damaged by diseases derived strength design. Five different proportions of dewatered fibres of Opuntia cactus white powder were used to produce mortars; the fibres were studied in percentages of $0.5,1,1.5,2$ and $4 \%$. The workability of the cement-sand mixture, and the normal consistency and setting times in the cementitious material-water pastes were evaluated. Tests performed on the mortars were simple compression, bending, tension and adhesion, at ages of 14, 28, 45, 90, 180 and 360 days. The particle shapes and cementing of the fibres were also characterized. Substitutions of under $2 \%$ yielded favorable results.
\end{abstract}

Keywords-mortar;opuntia cactus; addition

\section{INTRODUCTION}

The required properties of concrete can be specified by the mix design. Features may include the properties of the fresh concrete, the mechanical properties of the hardened concrete and inclusions, exclusions or limit-specific ingredients. The mix design leads to the development of the concrete specification. The proportioning (dosage) of the mixture refers to the process of determining the quantities of concrete ingredients. An adequately provided concrete must have the following qualities:

- Acceptable workability of fresh concrete

- Durability, strength and uniform appearance of hardened concrete

- Economy

After having chosen the features, one can obtain the relevant proportion mixing data from the field or laboratory. As most of the desired properties of the hardened concrete depend mainly on the quality of the cementitious paste, the first stage for the proportioning of concrete is the choice of an appropriate water-material relationship of the cementing (binder) for the resistance and durability required.

The water-cementitious material ratio (binder) is simply the mass of water divided by the mass of cementitious materials (Portland cement, blended cement, fly ash, slag, silica fume, natural pozzolan). The water/cementing ratio chosen for a mix design should be the least necessary to withstand the anticipated conditions of exposure. When durability is not the governing factor, the choice of the water-cementitious material ratio should be based on the compressive strength requirements.

Resistance (compression or bending) is the indicator of the quality of concrete most universally used. Although this is an important feature, other properties such as durability, permeability and wear resistance are recognized today as equally important or, in some cases, of greater importance, especially when considering the life of the structure [1].

Mineral additives can be used to improve the mechanical properties of the cement mix, due to their pozzolanic and/or cementitious nature. Besides improving the resistance of the mixture to cycles of freezing and defrosting [2], sulphate attack $[3,4,5]$ attack, alkali-aggregate [6] reaction and corrosion of reinforcing bars [7], mineral additives also serve to decrease the cost of the mix and provide improved workability of fresh concrete. In addition, fresh concrete mixtures containing mineral additives are less prone to bleeding [8].

Nopal (prickly pear)

The cactus belongs to the genus Opuntia, a cacti group containing about 300 varieties (some with thorns, others without) and is a common type of prickly cactus also known as Indian fig [9]. An important feature of the nopal is its high content of carbohydrates (glucose), which are grouped in large starch chains, which when considered as an additive in the manufacture of mortars for mixing water retention, promote the setting $[10,11,19]$. Cement pastes decrease the permeability, improve durability and increase the compressive strength [9, 20].

According to the technical article \# 328 of the SCT and IMT [9], preliminary results suggest that adding dehydrated cactus or aloe vera at low concentrations ( $\leq 2 \%$ by weight) as a replacement for cement may be desirable to increase the corrosion resistance of the reinforced concrete elements.

\section{EXPERIMENTAL PROCEDURE}

\section{A. Design and Testing Mixtures}

Based on previous studies, for the design of mixtures to use for experimentation, as shown in Table 1, the water/binder ratio was set at 1.01 (this was necessary to comply with the control 
mixture fluidity) for each of the sample mixtures it was careful to be fulfilled with the fluidity of the control. The fluidity of all blends was determined according to the ASTM C 1437-01 [12] procedure.

TABLE I. DESIGN OF MIXTURES TO BE ANALYZED.

\begin{tabular}{|c|c|c|c|c|c|c|}
\hline \multirow{2}{*}{ Parameter } & \multicolumn{6}{|c|}{ FN Substitutions } \\
\cline { 2 - 7 } & $\mathbf{0 \%}$ & $\mathbf{0 . 5 \%}$ & $\mathbf{1 . 0 \%}$ & $\mathbf{1 . 5 \%}$ & $\mathbf{2 . 0 \%}$ & $\mathbf{4 . 0 \%}$ \\
\hline CPC cement & 100.0 & 99.5 & 99.0 & 98.5 & 98.0 & 96.0 \\
\hline Substitute material & 0.0 & 0.5 & 1.0 & 1.5 & 2.0 & 4.0 \\
\hline $\begin{array}{c}\text { Cementing/ } \\
\text { water ratio }\end{array}$ & 1.01 & 1.01 & 1.01 & 1.01 & 1.01 & 1.01 \\
\hline $\begin{array}{c}\text { Cementing/ } \\
\text { sand ratio }\end{array}$ & 2.75 & 2.75 & 2.75 & 2.75 & 2.75 & 2.75 \\
\hline
\end{tabular}

For analysis of the resistance to axial load, ASTM C 109M [13] was followed. For the bending strength of mortars, the ASTM C 348-02 standard was followed [14]; both tests were run using the Tinius Olsen universal machine. For the stress test, the procedure of the Manual of Materials Analysis of the Faculty of Civil Engineering, UMSNH, Third Edition, was followed, using the Michaellis machine.

To carry out the adhesion test, the ASTM C 1583, 2004 [15] standard was followed. For the non-destructive testing of the pulse velocity, the ASTM C 597-02 standard was followed [16]; while for the density test the procedure described in the Materials Analysis Manual, UMSNH, Third Edition, was followed. After preparing the appropriate number of specimens for each mixture, the specified test ages were 14, 28, 45, 90, 180 and 360 days.

\section{B. Characterization of Fibres and Cement Employed}

Cement. The cement for this research was RS CPC 30R (NMX-C-414-0NNCCE, 2004 [17]). The shape of the CPC cement particles (Figure 1) is very similar to the materials and mineral ash, just as in the case of the $\mathrm{CPC}$ a wider range of sizes is observed.

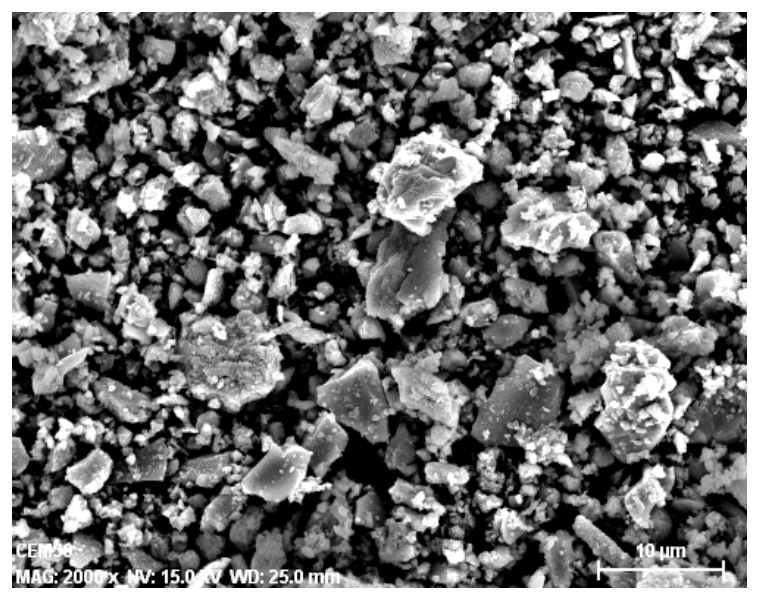

FIGURE I. IMAGE OF CPC PARTICLES

Opuntia white cactus fibres.For this material notest was performed to determine the size and distribution of particles, and it was used as provided by the manufacturer. The shape of the particles is much like FN pozzolans that are of plant origin, which is why thefibreshave elongated shapes (Figure 2).

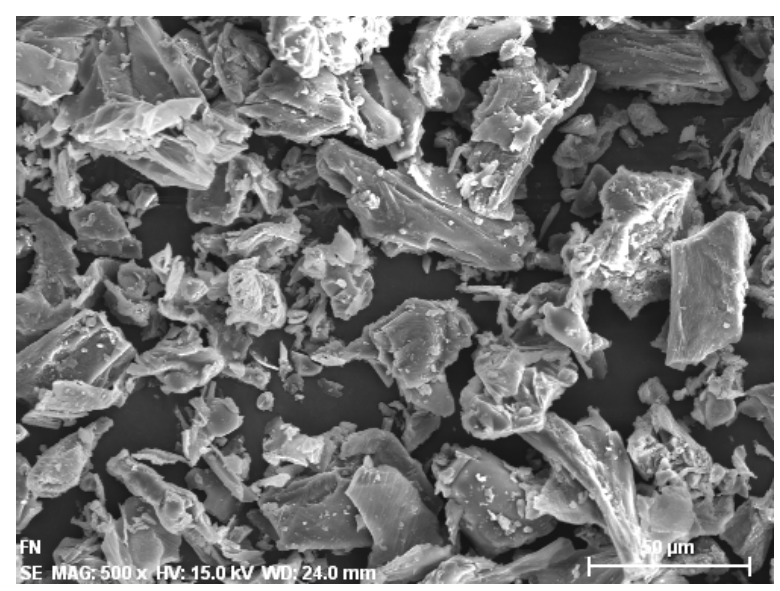

FIGURE II. FORM OF FN PARTICLES

\section{RESULTS}

\section{A. Normal Consistency of the Cement-Water Paste}

In Figure 3, we see how the FN shows a slightly lower water demand than the control paste for lower rates to $4 \%$. Since the hydrated Opuntia cactus fibres form a gel Redeemer of the cement matrix [19], this means that in the first percentages (Figure 3 ) the demand for water is less with respect to the control, as this would act as a gel plasticizer; but in amounts larger than $3 \%$, such as $4 \%$, the amount of fibres is high and hence the demand for water for hydration increases considerably, causing the loss of the lubricating property.

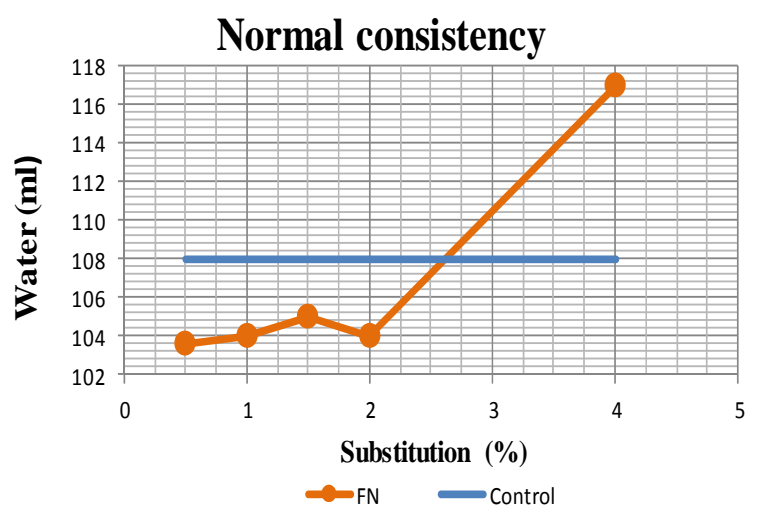

FIGURE III. NORMAL CONSISTENCY OF CONTROL AND FN

\section{B. Setting Times}

As shown in Figure 4, the initial setting times increase within a range of 2 to 5 hours, but in the control paste (cementwater) there is much variability in the percentages of substitution. This increase maybe due to a major benefit of the Opuntiacactus which contributes to the Portland cement-based mixture; by adding the Opuntiacactus mixture, this forms a gel that creates internal water traps and this reduces the rate of water transport into the matrix [19], increasing both the initial and final setting times (Figures 4 and 5). 


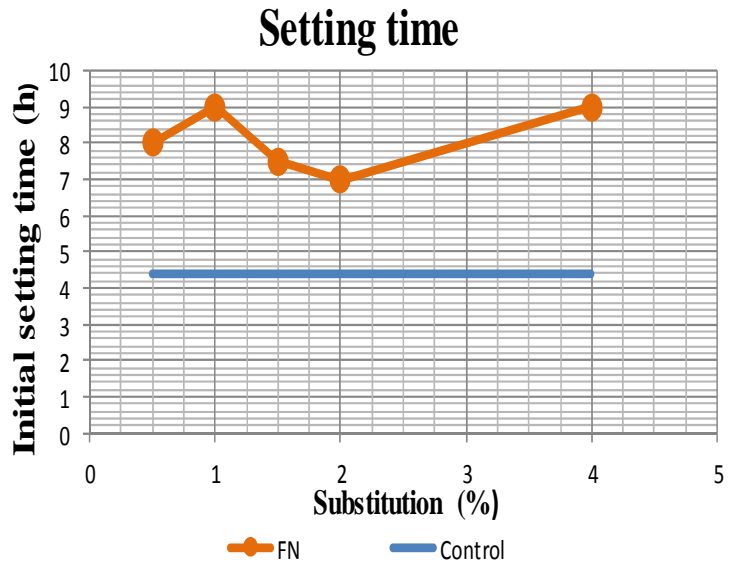

FIGURE IV. INITIAL SETTING TIME OF CONTROL AND FN

The final setting time (Figure 5) is increased for all the percentages tested within a range of 4 to 18 hours. The behaviour of the FN shows high variability between the substitution percentages.

The setting time test was performed following the method of Gillmore, according to ASTM C 266-03 [18].

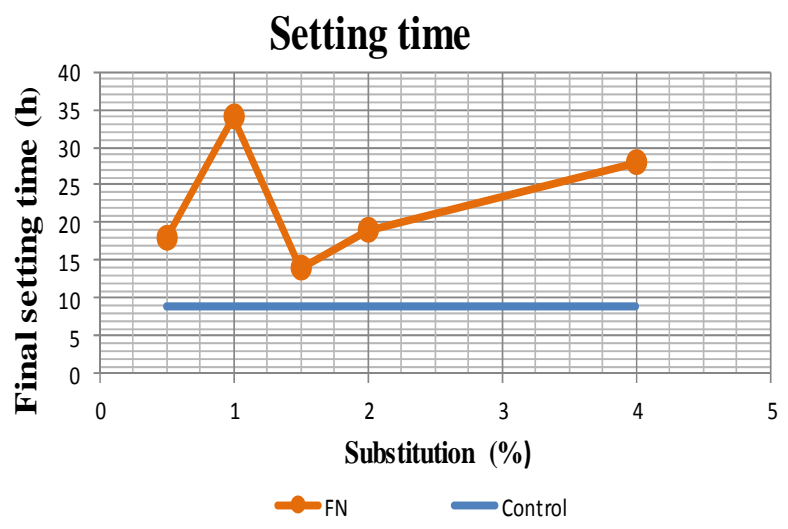

FIGURE V. FINAL SETTING TIME OF CONTROL AND FN

\section{Mechanical Tests}

Axial compression. The compression behavior of substitutions of 0.5 to $1.5 \%$ for ages of 90 and 180 days is superior to the control, but shows the same strength at the age of 360 days in all percentages except for the substitution of $2 \%$, which remains below the control for all the ages presented. In the five substitutions, an upward trend is observed from the age of 90 days, with substitutions of 0.5 and $1.5 \%$ showing a steady upward trend (Figure 6).

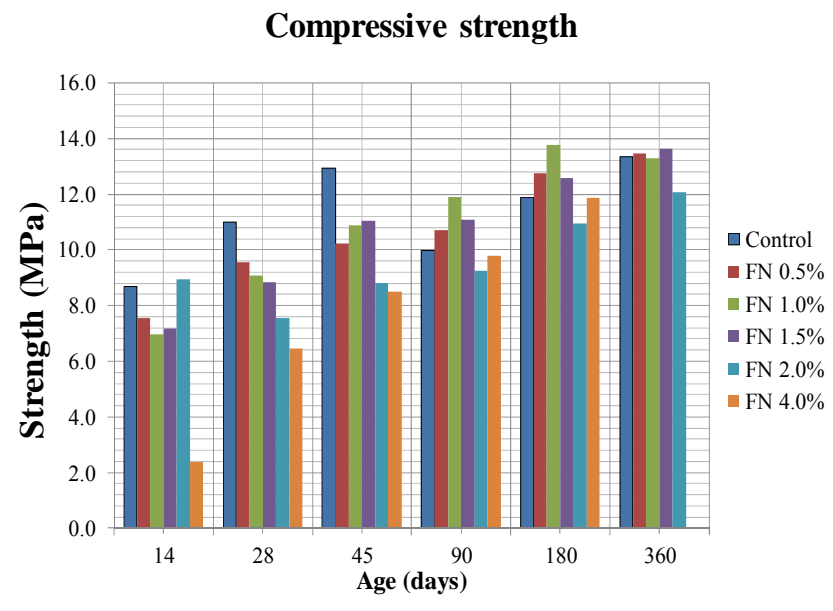

FIGURE VI. COMPRESSION BEHAVIOUR OF THE FN

Flexural strength. In Figure 7 the behaviour of the flexural FN shows greater variability than the graph of compressive strength, and is generally inferior to the control behaviour at an early age, while there are increases at the ages of 180 and 360 days for the 1 and $1.5 \%$ substitutions, after showing a positive and steady incline from 90 days of aging.

\section{Flexural strength}

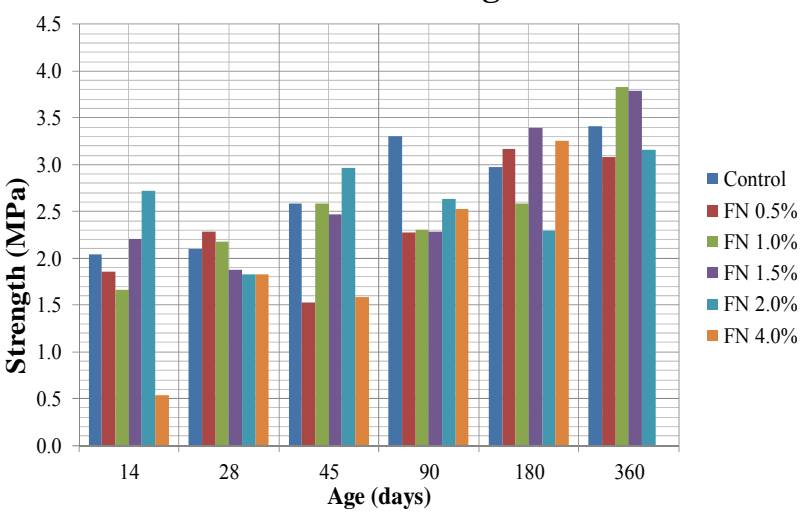

FIGURE VII. BENDING BEHAVIOUR OF THE FN

Tensile strength. Overall, the behavior for the three percentages was slightly above the control (Figure 8). In this graph we can distinguish two groups of behaviours, one that slightly exceeds the control (FN 1, 1.5 and $2 \%$ ); and the second group which is below it at virtually all ages, and includes the two extreme substitutions in this research (FN 0.5 and 4\%), which defines for us the range of effectiveness of the additive for soliciting voltage. Again the percentages of FN 1 and 1.5\% show the best performance. 


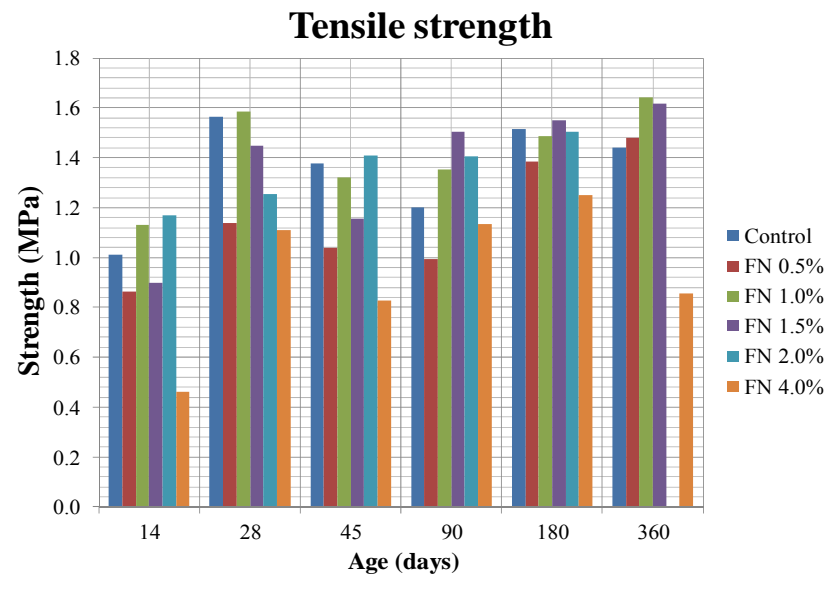

FIGURE VIII. BEHAVIOUR OF FN STRESS

Adherence. In this test the results are presented only up to 90 days of ageing. The FN shows an upward trend in almost all the substitutions (Figure 9). Four of the five substitutions surpass the control at the age of 90 days, with the best performance shown by the substitutions of 0.5 and $1 \%$, while FN $1.5 \%$ behaves parallel to and slightly above the control.

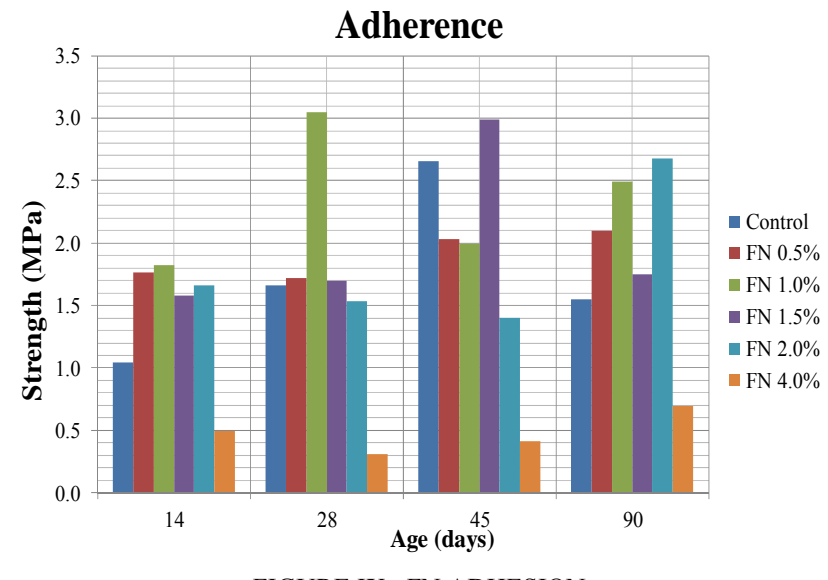

FIGURE IX. FN ADHESION

\section{CONCLUSIONS}

Most of the substitute materials studied in this research show a good performance in terms of the mechanical stresses, especially in excess of 180 days of age, but there were still few materials that exhibited good results in $100 \%$ of the tests, allowing us to limit the materials with optimum performance through the study presented here.

- Mixtures with optimal performance, which show consistent mechanical improvements and behaviour in tests with reduced water demandcloser to the control, with an initial setting time of about 3 hours more than the control and a final setting of 5 hours more than the control (the least of our analysis was mixtures). This is achieved with the substitution of $1.5 \% \mathrm{FN}$.

- Mixtures with an acceptable mechanical performance but with great variability in their water demand and in the time of initial and final setting; even that like mixing 1.5\% FN show upward trends which suggest that at older ages they may show a better performance in all the substitutions studied: these were found to be FN $0.5 \%$ and $1.0 \%$.

\section{ACKNOWLEDGMENTS}

The authors thank the Coordination of Scientific Research of the Universidad Michoacana de San Nicolas de Hidalgo and support facilities Materials Laboratory "Ing. Luis Silva Ruelas" of the Faculty of Civil Engineering; and PROMEP, the Thematic Network for the Conservation of Materials of Historic and Artistic Interest.

\section{REFERENCES}

[1] Paulo, H. and Pereira, F. (2003) Manual of rehabilitation of concrete structures. Repair, reinforcement and protection. Electronic version on CD, Sao Paulo, Brazil, 2003. ISBN 85-903707-1-2.

[2] Mardani-Aghabaglou, A., Andic-Cakir, O., and Ramyar, K. (2013) Freeze-thaw resistance and transport properties of high-volume fly ash concrete designed by roller compacted maximum density method. Cem. Concr. Compos., 37, 259-66.

[3] Vuk, T., Gabrovšek, R., and Kaucic, V. (2002) The influence of mineral admixtures on sulfate resistance of limestone cement pastes aged in cold MgSO4 solution. Cem. Concr. Res.,32 (6), 943-8.

[4] Atahan, H.N. and Dikme, D. (2011) Use of mineral admixtures for enhanced resistance against sulfate attack. Const. Build. Mater., 25 (8), 3450-7.

[5] Aydın, S., Yazıcı, H., Yigìter, H., and Baradan, B. (2007) Sulfuric acid resistance of high-volume fly ash concrete. Build. Environ., 42 (2), 717 21.

[6] Shafaatian, S.M.H., Akhavan, A., Maraghechi, H., and Rajabipour, F. (2013) How does mitigate fly ash alkali-silica reaction (ASR) in accelerated mortar bar test (ASTM C1567)? Cem. Concr. Compos., 37, 143-53.

[7] Shi, X., Yang, Z., Liu, Y.,and Cross, D. (2011) Strength and corrosion properties of Portland cement mortar and concrete admixtures with mineral. Const. Build. Mater., 25 (8), 3245-56.

[8] Mehta, P.K. and Monteiro, P.J.M. (2006) Concrete; microstructure, properties, and material. 3rd ed. New York, USA: McGraw-Hill.

[9] Torres, A. (2010) Additions based on cactus as a corrosion inhibitor for reinforcing steel in concrete. Technical Publication \# 328, Secretariat of Communications and Transportation, Mexican Institute of Transportation, Mexico.

[10] Moralez Garibay, M. (2009) Mechanical performance of mortar of lime added with dried fiber powder Opuntia cactus.Thesis. Morelia, Michoacan, Mexico: Faculty of Civil Engineering, Universidad Michoacana de San Nicolas de Hidalgo.

[11] Diaz Gonzales, N. (2011) Effect of coarse crushed stone aggregate in static and dynamic mechanical stresses. Hydraulic concrete case simply dried fibers added with white Opuntia cactus. Bachelor thesis. Morelia, Michoacan, Mexico: Faculty of Civil Engineering, UMSNH.

[12] ASTM C 1437-01: Standard Test Method for Flow of Hydraulic Cement Mortar.

[13] ASTM C 109M: Standard Test Method for Compressive Strength of Hydraulic Cement Mortars (using 2-in or 50-mm Cube Specimens).

[14] ASTM C 348-02: Standard Test Method for Flexural Strength of Hydraulic-Cement Mortars.

[15] ASTM C 1583. (2004)Standard Test Method for Tensile Strength of Concrete Surfaces and the Bond Strength or Tensile Strength of Concrete Repair and Overlay Materials by Direct Tension (Pull-off method).

[16] ASTM C 597-02.(2009) Standard Test Method for Pulse Velocity through Concrete.

[17] ISO-C-414 (2004) 0NNCCE Construction industry - Hydraulic Cement Specifications and test methods.

[18] ASTM C 266-03.Standard Test Method for Time of Setting of Hydraulic-Cement Paste by Gillmore Needles. 
[19] Martinez-Molina, W., Torres-Acosta, A.A., Martínez-Peña, G.E.I., Alonso Guzman, E., and Mendoza-Perez, I.N. (2015) Cement-based, materials-enhanced durability mucilage from opuntiaficus indicates additions. Title No. 112-M18, ACI Materials Journal. January-February 2015.

[20] Torres-Acosta, A.A., Martinez-Molina, W., and Alonso-Guzman, M.S. (2012) State of the art on cactus additions in alkaline media as corrosion inhibitors. International Journal of Corrosion, 2012, Article ID 646142 doi: $10.1155 / 2012 / 646142$. 